\title{
Essential role of sphingosine 1-phosphate receptor 2 in pathological angiogenesis of the mouse retina
}

\author{
Athanasia Skoura, ${ }^{1}$ Teresa Sanchez, ${ }^{1}$ Kevin Claffey, ${ }^{1}$ Suzanne M. Mandala, ${ }^{2}$ \\ Richard L. Proia, ${ }^{3}$ and Timothy Hla ${ }^{1}$
}

${ }^{1}$ Center for Vascular Biology, University of Connecticut Health Center, Farmington, Connecticut, USA. ${ }^{2}$ Merck Research Laboratories, Rahway, New Jersey, USA. ${ }^{3}$ Genetics of Disease and Development Branch, NIDDK, NIH, Bethesda, Maryland, USA.

\begin{abstract}
Sphingosine 1-phosphate (S1P), a multifunctional lipid mediator that signals via the S1P family of G protein-coupled receptors (S1PR), regulates vascular maturation, permeability, and angiogenesis. In this study, we explored the role of $S 1 P 2$ receptor $\left(S 1 P_{2} R\right)$ in normal vascularization and hypoxia-triggered pathological angiogenesis of the mouse retina. $S 1 P_{2} R$ is strongly induced in ECs during hypoxic stress. When neonatal mice were subjected to ischemia-driven retinopathy, pathologic neovascularization in the vitreous chamber was suppressed in $\mathrm{S1p}^{-/-}$mice concomitant with reduction in endothelial gaps and inflammatory cell infiltration. In addition, EC patterning and normal revascularization into the avascular zones of the retina were augmented. Reduced expression of the proinflammatory enzyme cyclooxygenase-2 (COX-2) and increased expression of eNOS were observed in the $S 1 \mathrm{p}^{-/-}$mouse retina. $S 1 \mathrm{P}_{2} \mathrm{R}$ activation in ECs induced COX-2 expression and suppressed the expression of eNOS. These data identify the $S 1 P_{2} R$-driven inflammatory process as an important molecular event in pathological retinal angiogenesis. We propose that antagonism of the $S_{1} P_{2} R$ may be a novel therapeutic approach for the prevention and/or treatment of pathologic ocular neovascularization.
\end{abstract}

\section{Introduction}

Sphingosine 1-phosphate (S1P) is a lipid mediator that regulates various biological processes, such as cell proliferation, migration, survival, and differentiation (1). S1P, generated by the phosphorylation of sphingosine by sphingosine kinase 1 and 2 (Sphk1 and Sphk2), is degraded by S1P-specific phosphatases and a lyase (1). It is also a high-affinity ligand for $5 \mathrm{G}$ protein-coupled S1P receptors, $\mathrm{S}_{1} \mathrm{P}_{1} \mathrm{R}, \mathrm{S}_{1} \mathrm{P}_{2} \mathrm{R}, \mathrm{S}_{1} \mathrm{P}_{3} \mathrm{R}, \mathrm{S}_{1} \mathrm{P}_{4} \mathrm{R}$, and $\mathrm{S}_{1} \mathrm{P}_{5} \mathrm{R}$, which regulate distinct intracellular signaling pathways $(2,3)$. S1P $\mathrm{P}_{1} \mathrm{R}, \mathrm{S}_{\mathrm{P}} \mathrm{P}$, and $\mathrm{S}_{1} \mathrm{P}_{3} \mathrm{R}$ are widely expressed, whereas $\mathrm{S}_{1} \mathrm{P}_{4}$ and $\mathrm{S}_{1} \mathrm{P}_{5}$ expression is prominent in cells of the immune and nervous systems, respectively. $\mathrm{S}_{1} \mathrm{P}_{1}$ receptor couples exclusively to $\mathrm{G}_{\mathrm{i}}$ signaling pathway, whereas $\mathrm{S}_{1} \mathrm{P}_{2}$ and $\mathrm{S}_{1} \mathrm{P}_{3}$ receptors couple to $\mathrm{G}_{\mathrm{i}}, \mathrm{G}_{\mathrm{q}}$, and $\mathrm{G}_{12 / 13}$ pathways. However, $\mathrm{S}_{1} \mathrm{P}_{2}$ activates $\mathrm{G}_{12 / 13}$ potently, whereas $\mathrm{S}_{1} \mathrm{P}_{3}$ activates $G_{q}$ preferentially $(4,5)$.

$\mathrm{S} 1 \mathrm{P}$ receptors regulate important physiological functions of the vascular system, such as vascular morphogenesis and maturation, cardiac function, vascular permeability, and tumor angiogenesis (6-10). Indeed, S1p1 receptor-null embryos die due to hemorrhage at E12.5-E14.5. We found that the $\mathrm{S}_{1} \mathrm{P}_{1} \mathrm{R}$ signaling in ECs promotes the formation of strong $\mathrm{N}$-cadherin-based junctions between endothelial and vascular smooth muscle cells and thus stabilizes the nascent vasculature $(11,12)$. However, mice that lack either the $\mathrm{S}_{1} \mathrm{P}_{2} \mathrm{R}$ or the $\mathrm{S}_{1} \mathrm{P}_{3} \mathrm{R}$ are viable and fertile. Interestingly, S1p1/S1p2-double-null embryos showed a more severe phenotype than $\mathrm{S} 1 \mathrm{p} 1$-single-null embryos, suggesting that $\mathrm{S}_{1} \mathrm{P}_{2} \mathrm{R}$ also regu-

Nonstandard abbreviations used: Ang-2, angiopoietin-2; COX-2, cyclooxygenase-2; GCL, ganglion cell layer; GFAP, glial fibrillary acidic protein; GS-lectin, Griffonia simplicifolia lectin; INL, inner nuclear layer; RCA I, Ricinus communis agglutinin I; ROP, retinopathy of prematurity; $\mathrm{S} 1 \mathrm{P}$, sphingosine 1 -phosphate; $\mathrm{S} 1 \mathrm{P}_{2} \mathrm{R}, \mathrm{S} 1 \mathrm{P} 2$ receptor. Conflict of interest: The authors have declared that no conflict of interest exists. Citation for this article: J. Clin. Invest. 117:2506-2516 (2007). doi:10.1172/JCI31123. lates embryonic vascular development and that these 2 receptors cooperate with each other (13). In addition, S1p2-null mice are profoundly deaf due to vascular abnormalities in the stria vascularis of the inner ear and degeneration of sensory hair cells of the organ of Corti $(14,15)$. Moreover, a mutation in the zebrafish gene milesapart (Mil), an S1p2 ortholog, results in cardiac developmental defects (cardia bifida) due to defective migration of cardiomyocyte precursors, underscoring the significance of this receptor for fish cardiac development (16). However, the role of $\mathrm{S}_{1} \mathrm{P}_{2} \mathrm{R}$ in vascular development and pathology is virtually unknown.

In order to investigate the role of $\mathrm{S}_{1} \mathrm{P}_{2} \mathrm{R}$ in mammalian vascular development, we studied retinal vascular development of mice lacking $\mathrm{S}_{1} \mathrm{P}_{2} \mathrm{R}$ under physiological (normal retina development) and pathophysiological conditions (ischemia-driven retinopathy). Postnatal vascular development of the mouse retina provides an attractive model system for exploring the mechanisms of angiogenesis and vascular stabilization $(17,18)$. After birth, ECs emerge from the optic disc and form the primary vasculature of the mouse retina. Growing vessels with radial orientation are formed along the retina neuronal and astrocytic plexus. On the other hand, pathological retina angiogenesis produces abnormally growing and chaotically oriented dysfunctional vessels that grow into the vitreous as vascular tufts (19). This is common in the pediatric retinopathy of prematurity (ROP) condition and in diabetic retinopathy of the adult.

In this study, we show that the angiogenic process proceeds normally in $S 12^{-/-}$mice during normal retinal development. However, when mice were exposed to ischemic stress, $S 1 \mathrm{p}^{-/-}$retinas had reduced pathological intravitreal angiogenesis and apparently normal vascular development in the retina. We further demonstrate that $\mathrm{S}_{1} \mathrm{P}_{2} \mathrm{R}$ is required for inflammatory cell infiltration, induction of the proinflammatory and proangiogenic enzyme cyclooxygenase-2 (COX-2), and the suppression of eNOS, which produces the vasodilator NO. The current study identifies S1P 

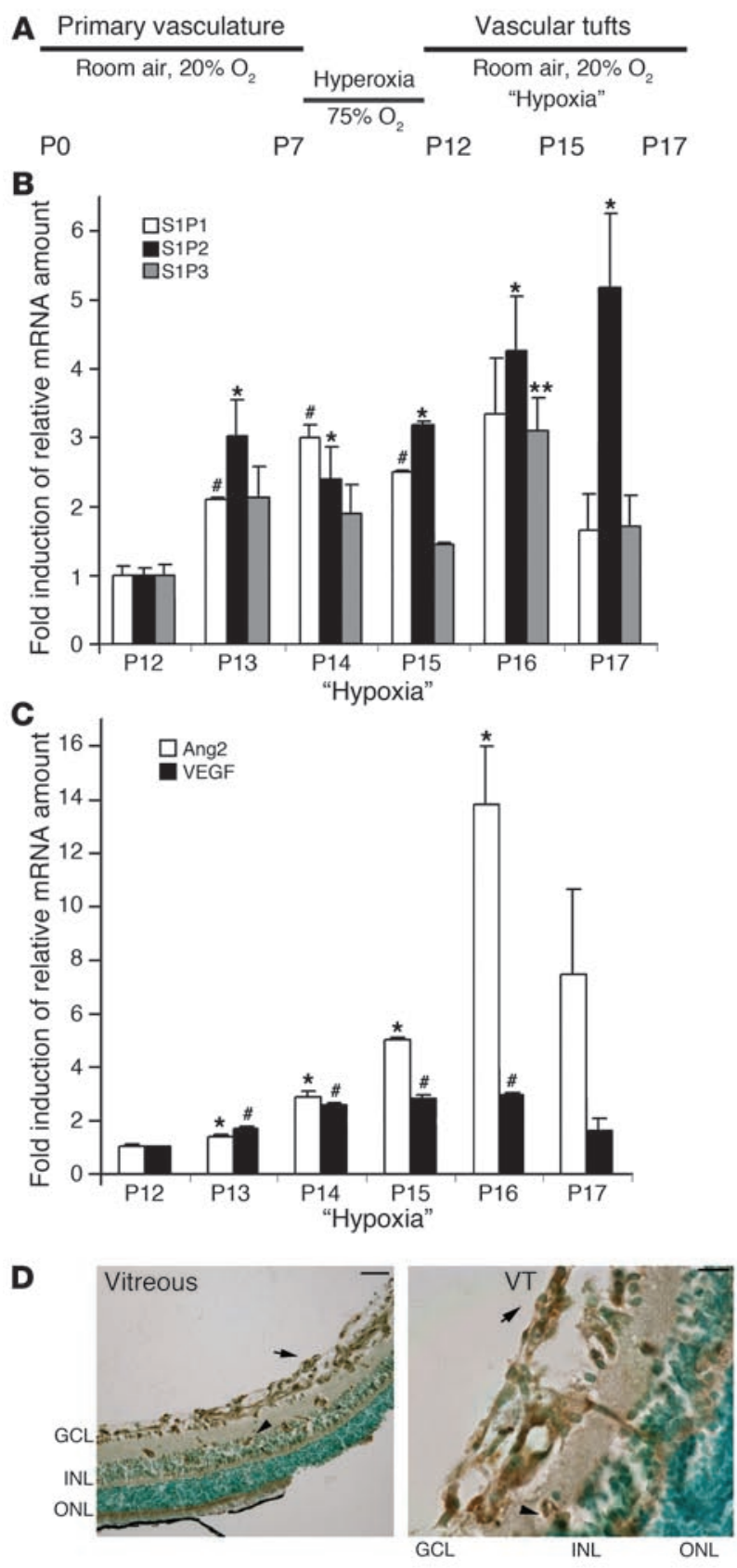

signaling by the $\mathrm{S}_{1} \mathrm{P}_{2} \mathrm{R}$ as a novel target for the prevention and/or treatment of vision-threatening retinopathies.

\section{Results}

$S 1 P_{2} R$ expression during ischemia-induced retinal angiogenesis. In order to evaluate whether $\mathrm{S} 1 \mathrm{P}$ receptors play a role in retina neovascularization, we investigated the expression of S1P receptors in a mouse model of retinal ischemia (20). After pups and their nursing mothers had been exposed to $75 \%$ oxygen (hyperoxia) for 5 days (P7-P12), the capillary network of the central retina regressed (vascular obliteration). At P12, pups and their nursing mothers were returned back to room air ("hypoxia"). Resultant retinal ischemia initiated rapid vessel growth; however, pathologic angiogenesis occurred in the vitreous, reaching a maximum at P17 (Figure 1A).

\section{Figure 1}

$\mathrm{S}_{1} \mathrm{P}_{2} \mathrm{R}$ expression in the course of ischemia-induced pathologic retinal angiogenesis. (A) Schematic representation of hypoxia-induced mouse model of ROP. (B) $\mathrm{S}_{1} \mathrm{P}_{1}, \mathrm{~S}_{1} \mathrm{P}_{2}$, and $\mathrm{S}_{1} \mathrm{P}_{3}$ mRNA expression at P12 ("Hypoxia," day 0) was determined by quantitative RT-PCR analysis $(n=3)$. $\mathrm{S}_{1} \mathrm{P}_{2} \mathrm{R}$ expression was upregulated by 3 -fold at P13 (24 hours of hypoxia; ${ }^{*} P<0.035$ ) compared with P12 and was further increased by 5 -fold at P17 (5 days of hypoxia; ${ }^{*} P<0.035$ ). $\mathrm{S}_{1} \mathrm{P}_{1}$ expression was upregulated by 3 -fold at $\mathrm{P} 14$ (2 days of hypoxia; $\# P<0.01$ ). $\mathrm{S} 1 \mathrm{P}_{3}$ expression was induced by 3 -fold at $\mathrm{P} 16$ (4 days of hypoxia; ${ }^{\star \star} P<0.03$ ). (C) Ang-2 and VEGF mRNA in the course of hypoxia $(n=3)$. Ang-2 expression was 14 -fold higher at P16 (4 days of hypoxia; $\left.{ }^{*} P<0.015\right)$. VEGF expression was induced by 3 -fold at $\mathrm{P} 16$ (4 days of hypoxia; ${ }^{\#} P<0.0015$ ). (D) Immunohistochemical localization of $\mathrm{S}_{1} \mathrm{P}_{2} \mathrm{R}$ in $\mathrm{P} 17$ hypoxic retinal cross sections. $\mathrm{S}_{1} \mathrm{P}_{2} \mathrm{R}$ was detected in the GCL, showing a vessel-like distribution pattern (arrow) and in the INL (arrowhead). Scale bar: $100 \mu \mathrm{m}$. At a higher magnification (right panel), $\mathrm{S}_{1} \mathrm{P}_{2} \mathrm{R}$ immunodetection revealed a strong signal in the INL (arrowhead) as well as in vascular tufts (VT; arrow); scale bar: $10 \mu \mathrm{m}$. Nuclear counterstaining was with methyl green.

The expression level of ubiquitously expressed S1P receptors, namely $\mathrm{S}_{1} \mathrm{P}_{1}, \mathrm{~S}_{1} \mathrm{P}_{2}$, and $\mathrm{S}_{1} \mathrm{P}_{3}$, was measured by quantitative realtime RT-PCR assay (Figure 1B). Expression of all 3 receptors was detected at $\mathrm{P} 12$ before the onset of relative hypoxia. Interestingly, at $\mathrm{P} 13$ (24 hours of relative hypoxia) $\mathrm{S} 1 \mathrm{P}_{2} \mathrm{R}$ mRNA level was increased 3 -fold $(P<0.035 ; n=3)$. The receptor expression increased further to 5 -fold at P17 (5 days of relative hypoxia; $P<0.035 ; n=3$ ) at the growth phase of pathologic angiogenesis. However, mRNA levels of $\mathrm{S}_{1} \mathrm{P}_{1}$ and $\mathrm{S}_{1} \mathrm{P}_{3}$ receptors increased modestly during the course of relative hypoxia and returned to baseline levels by P17 (Figure 1B). As expected, ischemia enhanced retinal expression of VEGF mRNA by more than 2.5 -fold $(P<0.0015 ; n=3$; P16) and angiopoietin-2 (Ang-2) expression by 14 -fold $(P<0.015 ; n=3$; P16), which is consistent with previous reports that describe VEGF and Ang-2 as hypoxia-induced regulators of retinal angiogenesis (Figure 1C) $(21,22)$. In contrast, during the course of normal retina development (normoxia), $\mathrm{S}_{1} \mathrm{P}_{2} \mathrm{R}$ expression sharply declined during the first week of vascular development (P5-P10) and remained at low levels (P15 and P28) (Supplemental Figure 1A; supplemental material available online with this article; doi:10.1172/JCI31123DS1).

Prompted by the observation that $\mathrm{S}_{1} \mathrm{P}_{2}$ mRNA expression is significantly increased during the course of relative hypoxia, we localized the cells that express this receptor in the retina. The $\mathrm{S}_{1} \mathrm{P}_{2}$ antibody detected an appropriately sized $(\sim 40-\mathrm{kDa}) \mathrm{mol}-$ ecule in Western blot analysis of protein extracts of VSMCs and mouse embryonic fibroblasts that endogenously express $S 1 \mathrm{P}_{2} \mathrm{R}$ as well as of HEK293 cells transfected with the $\mathrm{S}_{1} \mathrm{P}_{2} \mathrm{R}$. (Supplemental Figure 2). These observations suggest that the antibody is specific in the detection of $\mathrm{S}_{1} \mathrm{P}_{2}$ antigen. $\mathrm{S}_{1} \mathrm{P}_{2} \mathrm{R}$ was detected by immunohistochemistry in retinal cross sections around the optic nerve area at $\mathrm{P} 17 . \mathrm{S}_{1} \mathrm{P}_{2}$ staining exhibited vessel-like distribution in the ganglion cell layer (GCL; arrows) and in the inner nuclear layer (INL; arrowheads) of hypoxic retinas. However, there was no immunoreactivity in the avascular outer nuclear layer (Figure $1 \mathrm{D})$. At a higher magnification, it was evident that $\mathrm{S}_{1} \mathrm{P}_{2} \mathrm{R}$ is expressed in ECs of INL as well as in the primary vasculature of GCL, where $\mathrm{S}_{1} \mathrm{P}_{2}$ expression highlighted vascular tuft-like structures that abnormally sprout at the interface between vitreous and retina (Figure 1D). Although these data do not rule out nonvascular expression of $\mathrm{S}_{1} \mathrm{P}_{2}$, these observations suggest that $\mathrm{S}_{1} \mathrm{P}_{2} \mathrm{R}$ 

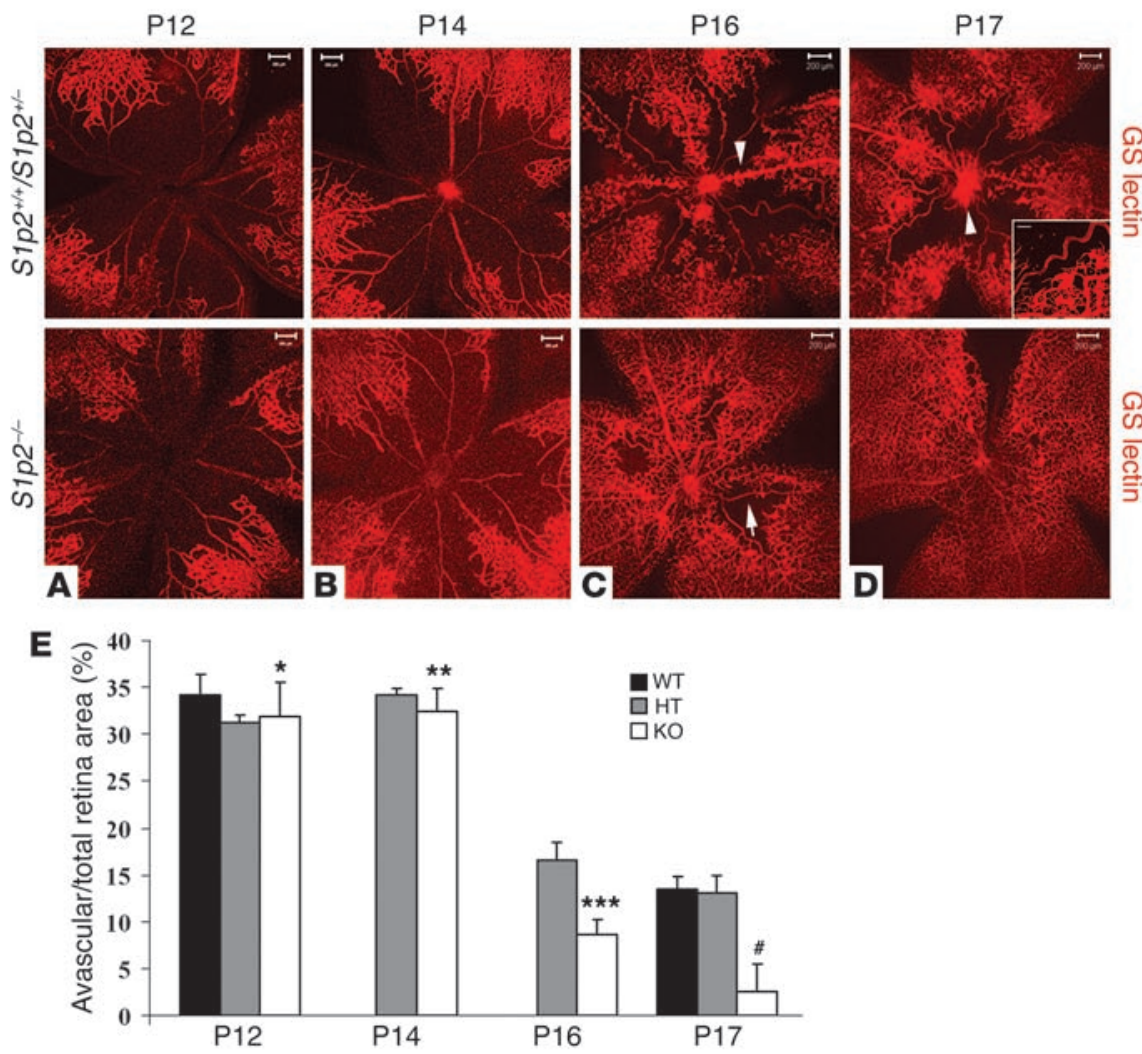

$S 1 p 2^{+/+}$

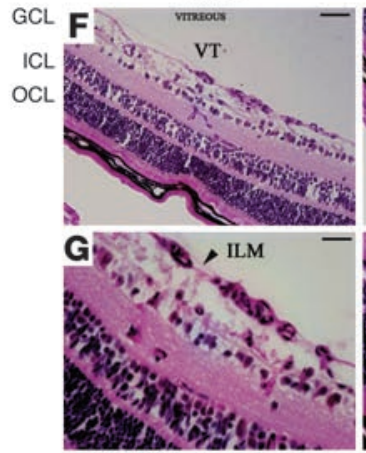

P17

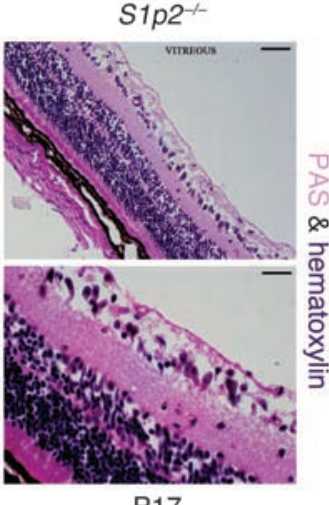

P17

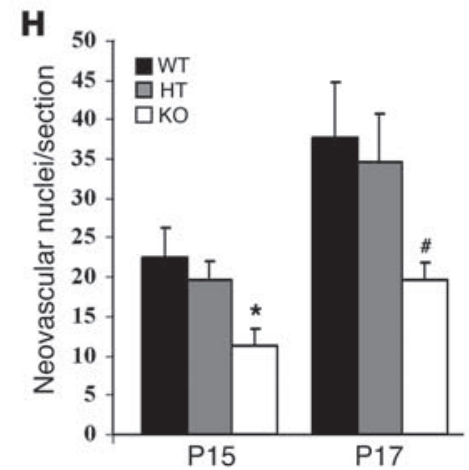

Figure 2

$S 1 p 2^{-/-}$retinas display increased intraretinal vascularization and decreased intravitreal neovascularization during the course of hypoxia. (A and E) At P12, vascular obliteration was similar in S1p2 $2^{+/}(34.2 \% \pm 2.14 \%$; $n=4), S 1 p 2^{+/-}(31.2 \% \pm 0.9 \% ; n=3)$, and $S 1 p 2^{-1-}$ whole mount retinas $(31.9 \% \pm 3.6 \%$; $n=2,{ }^{*} P=0.37$ ) stained for GS-lectin. (B and E) At P14, vascular obliteration was also similar in S1p2+/- $(34.19 \% \pm 0.74 \%$; $n=3)$ and $S 1 p 2^{--}(32.49 \% \pm 2.4 \% ; n=6$; ${ }^{* \star} P=0.1$ ) retinas. (C and $\mathbf{E}$ ) At $\mathrm{P} 16, S 1 p 2^{+/-}$ retinas developed abnormal buds (arrowhead), and the capillary-free area was $16.6 \% \pm 1.9 \%(n=3) ; S 1 p 2^{-/-}$retinas had improved vascular morphology (arrow) and reduced capillary-free area $(8.6 \% \pm 1.7 \%$; $\left.n=7 ;{ }^{* *} P<0.001\right)$. (D and E) At P17, $S 1 p 2^{+/+}(n=2)$ and S1p2 $2^{+/-}(n=11)$ retinas displayed $13.5 \% \pm 1.3 \%$ and $13.15 \% \pm 1.8 \%$ vascular obliteration, respectively, and increased neovascularization (arrowhead, inset; scale bar: $100 \mu \mathrm{m})$; $S 1 p 2^{-/-}$retinas $(n=9)$ showed significantly decreased capillary-free area $(2.6 \% \pm 2.9 \%$; $\# P<0.0001)$. Scale bar: $200 \mu \mathrm{m}$. (F and G) At P17, PAS and hematoxylin-stained cross section of $S 1 p 2^{+/+}$retinas with evident formation of vascular tufts (VT). (H) At P15, the mean number of neovascular nuclei/section for $S 1 p 2^{+/+}$and $S 1 p 2^{+/-}$was $22.5 \pm 3.7(n=2)$ and $19.58 \pm 2.43(n=4)$, respectively. $S 1 p 2^{-/-}$retinas showed a decreased number, $11.27 \pm 2.16\left(n=4 ;{ }^{*} P<0.0025\right)$. At $\mathrm{P} 17$, the mean number of neovascular nuclei/section for $S 1 \mathrm{p2}^{+/+}$and $S 1 \mathrm{p2^{+/- }}$ retinas was $37.6 \pm 7.03(n=3)$ and $34.528 \pm 6.2$ $(n=5)$, respectively. $S 1 p 2^{-/-}$retinas displayed a reduced number, $19.62 \pm 2.2(n=6$; $\# P<0.001)$. Scale bar: $100 \mu \mathrm{m}(\mathbf{F})$ and 10 $\mu \mathrm{m}(\mathbf{G})$. Values represent mean $\pm \mathrm{SD}$. HT, heterozygous. is induced in ischemic retinal endothelium and underscore the possibility that its signaling in the endothelium is important in hypoxia-driven neovascularization.

Enhanced intraretinal revascularization in $S 1 p 2^{-/-}$mouse retina. We next examined the phenotypes of $S 1 \mathrm{p}^{+/+}$and $S 1 \mathrm{p}^{2^{-/-}}$retinal whole mounts stained en face with Griffonia simplicifolia lectin (GS-lectin) at the peak of neovascularization (P17) (Figure 2D). Interestingly, we observed that $S 1 p 2^{-/-}$retinas developed enhanced intraretinal revascularization, whereas the $S 1 p 2^{+/+}$littermates showed increased avascular areas and formation of pathologic neovascular tufts, which is the expected phenotype of the ROP model (Figure 2D). To further study the role of $\mathrm{S}_{1} \mathrm{P}_{2} \mathrm{R}$ in intraretinal revascularization, we imaged GS-lectin-stained retinal whole mounts at different stages during the course of the ROP model. In particular, we measured avascular areas as percentage of total retinal area in $S 1 p 2^{+/+}, S 1 p 2^{+/-}$, and $S 1 p 2^{-/-}$mice. At P12, vascular obliteration occupied approximately $35 \%$ of the total retinal surface in $S 1 p 2^{+/+}(34.2 \% \pm 2.14 \%)$ as well as in $S 1 p 2^{+/-}(31.2 \% \pm 0.9 \%)$ and $S 1 p 2^{-/-}$littermates $(31.9 \% \pm 3.6 \% ; P=0.37$; Figure 2 , A and $E)$. At P14 (2 days of hypoxia), no significant difference was observed in the avascular area of S1p2+/- $(34.19 \% \pm 0.74 \%)$ or $S 1 p 2^{-/-}$mice $(32.49 \% \pm 2.4 \% ; P=0.1)$ (Figure 2, B and E). Extensive revascularization in $S 1 p 2^{+/-}$retinas was evident at P16 (4 days of hypoxia; Figure 2C); $S 1 p 2^{-/-}$retinas showed a significant decrease in capillary-free area $(16.6 \% \pm 1.9 \%$ versus $8.6 \% \pm 1.7 \% ; P<0.001$; Figure $2 \mathrm{E})$. The difference was most prominent at $\mathrm{P} 17(13.5 \% \pm 1.3 \%$ versus $2.6 \% \pm 2.9 \%$ of the total area; $P<0.0001$; Figure $2 \mathrm{E})$. In the WT animals, the vessels were tortuous and dilated with evident abnormal vascular growth between vascularized periphery and capillary-free central area, peaking around the optic disc area (Figure $2 \mathrm{D}$, inset), indicating that $S 1 \mathrm{p}^{-{ }^{--}}$retinas display normal vascular patterning and development during hypoxic insult. 

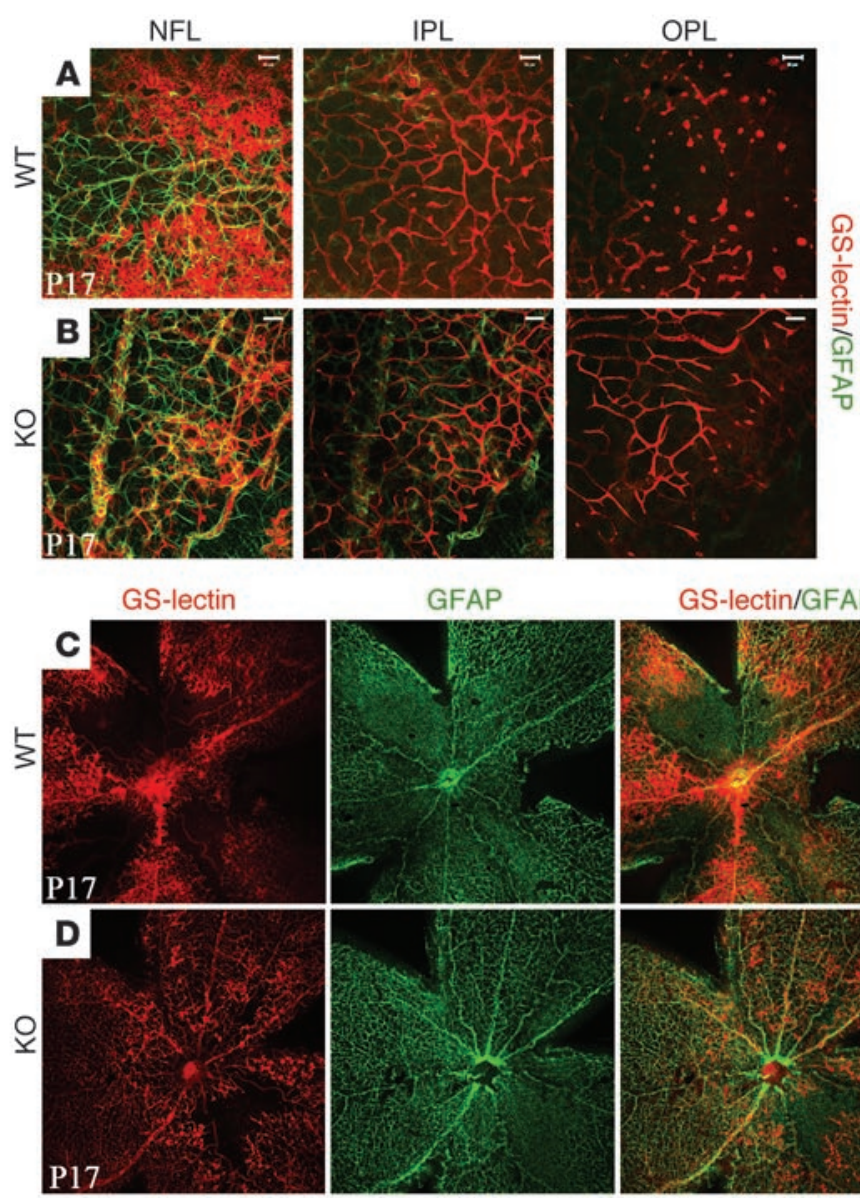

GS-lectin/GFAP
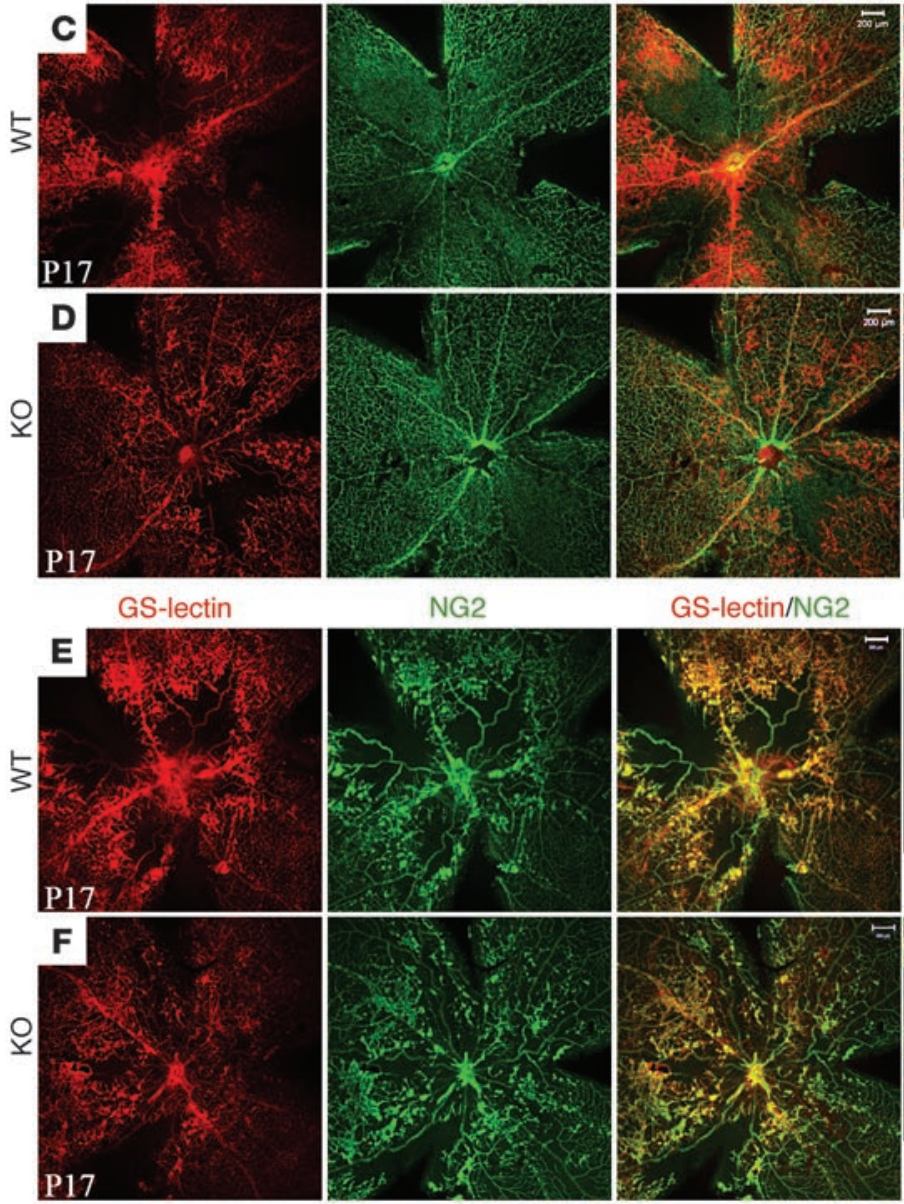

GS-lectin/NG2
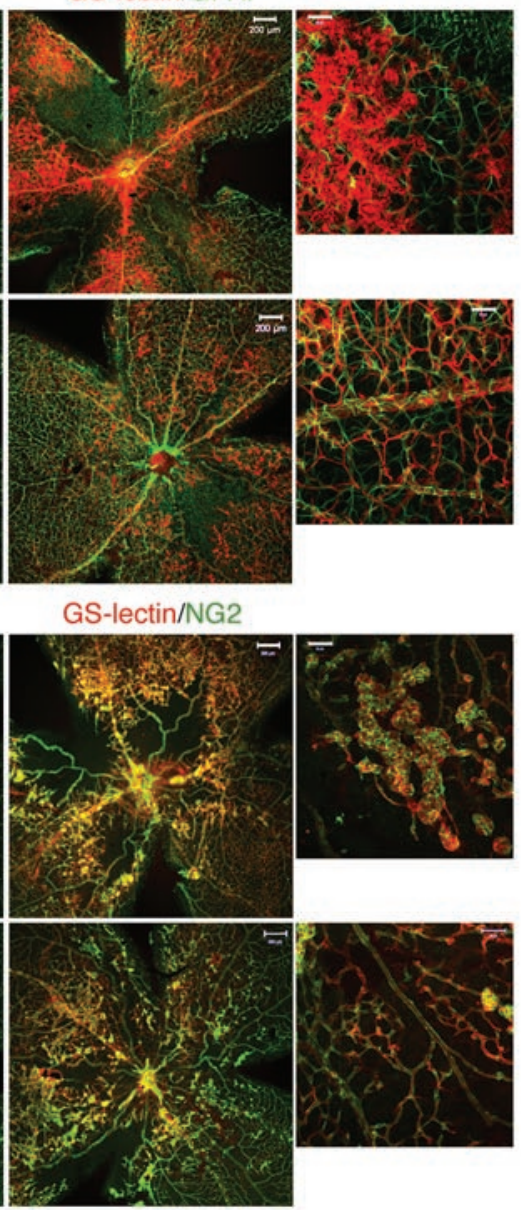

\section{Figure 3}

Ischemic $S 1 p 2^{-/-}$mouse retinas display normal vascular morphology. At P17, hypoxic $S 1 p 2^{-/-}$retinas formed all 3 vascular networks in the nerve fiber layer (NFL), inner plexiform layer (IPL), and outer plexiform layer (OPL), whereas $S 1 p 2^{+/+}$retinas form an incomplete OPL vascular bed (A and B), costaining with GFAP (astrocytes). At P17, in KO retinas (D) astrocytes (GFAP) were in close association with vessels (GS-lectin), whereas in WT animals (C), an increased number of abnormal tufts limited interaction with astrocytic processes. ( $E$ and $\mathbf{F}) \mathrm{WT}$ and $\mathrm{KO}$ retinas stained for pericyte marker (NG2). Scale bars: $200 \mu \mathrm{m}$ (C-F) and $50 \mu \mathrm{m}$ (A, B, and high-magnification views in $\mathbf{C}-\mathbf{F})$.

tal Figure 1, C and D) (23). Moreover, there was no obvious difference between the WT and $\mathrm{KO}$ counterparts in terms of vascular maturation and arteriovenous pattern formation as evidenced by $\alpha$-SMA staining of whole mount retinas (Supplemental Figure $1 \mathrm{E})$. These observations suggest that $\mathrm{S}_{1} \mathrm{P}_{2} \mathrm{R}$ is induced and modulates retina vascular development under hypoxic conditions, whereas it is dispensable for vascular development during the course of normal retina development.

Abnormal angiogenesis is attenuated in the intravitreal region of $S 1 \mathrm{p}^{-/-}$mice. Intravitreal angiogenesis was determined by counting the nuclei of growing vessels that extend beyond the interface between the retina and vitreous (inner limiting membrane) of PAS and hematoxylin-stained serial cross sections (Figure 2, F and G). $S 1 p 2^{+/+}$and $S 1 p 2^{-/-}$ mice maintained in normoxia did not show intravitreal angiogenesis (data not shown). At P15, when pathological tufts start developing, the mean number of nuclei counted for $S 1 p 2^{+/+}$and $S 1 p 2^{+/-}$retinas was $22.5 \pm 3.7$ and $19.58 \pm 2.43$, respectively. The mean number of neovascular nuclei for $S 1 \mathrm{p}^{-/-}$retinas was $11.27 \pm 2.16(P<0.0025$; Figure $2 \mathrm{H})$. At P17, when intravitreal neovascularization reached a maximum, the mean number of nuclei counted for $S 1 p 2^{+/+}$and $S 1 p 2^{+/-}$retinas that form vascular tufts (VT) was $37.6 \pm 7.03$ and $34.528 \pm 6.2$, respectively (Figure $2 \mathrm{H}$ ). In

Furthermore, detailed examination of frozen retinal cross sections during normal development (normoxia) revealed that developing vessels (GS-lectin-staining) of $S 12^{-/-}$retinas (P6) spread finely toward the periphery of the retina and are able to form additional capillary networks in inner plexiform (IPL) and outer plexiform layers (OPL) (P12 and P20) similar to their WT littermates (Supplemental Figure 1B). In addition, vessels of $S 1 \mathrm{p}^{-/-}$normoxic retinas appeared to follow the well-defined astrocytic plexus, while $S 1 p 2^{-/-}$ECs (tip cells) at the leading edge of the growing vessels displayed long filopodia similar to the WT counterparts (Supplemen- sharp contrast, the mean number of neovascular nuclei of $S 1 p^{-1}$ retinas was reduced by approximately 50\% (19.62 $\pm 2.2 ; P<0.001$; Figure $2 \mathrm{H}$ ). These data suggest that animals that lack $S 1 p 2$ receptor display greatly reduced pathological intravitreal neovascularization starting at the early stages of the disease.

Ischemic S1p2-/- mouse retinas display normal vascular morphology. In order to characterize the enhanced intraretinal revascularization in more detail, we imaged GS-lectin-stained $S 1 p 2^{+/+}$and $S 1 p 2^{-/-}$ whole mount retinas at P17 in the mid-peripheral region. Ischemic S1p2-/- retinas exhibited nearly complete and well-defined 

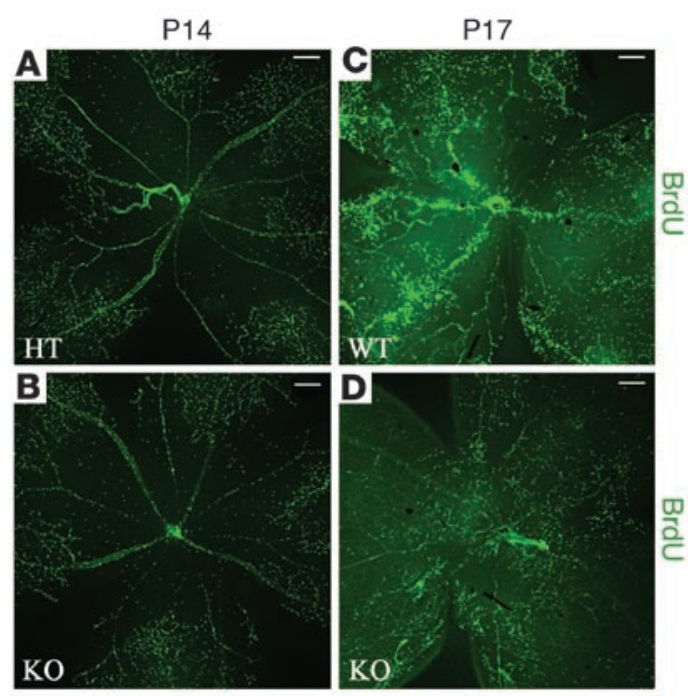

GS-lectin/BrdU
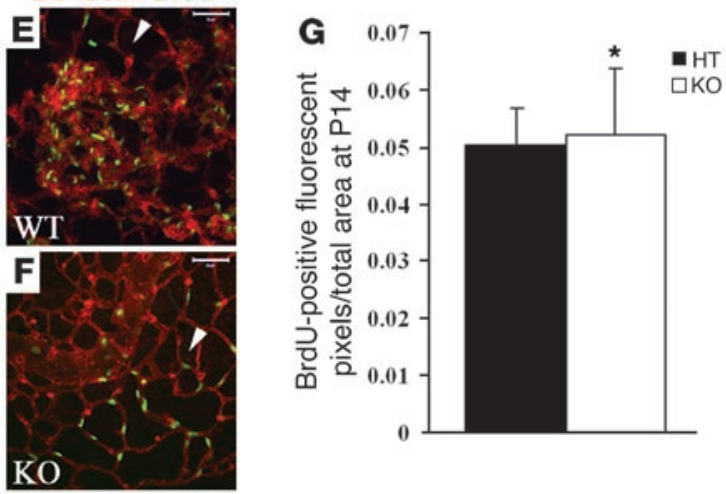

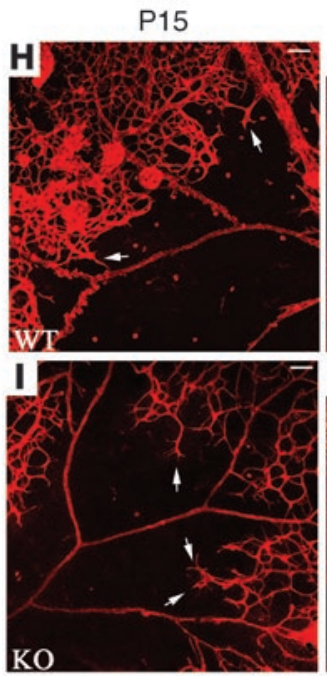

GS-lectin

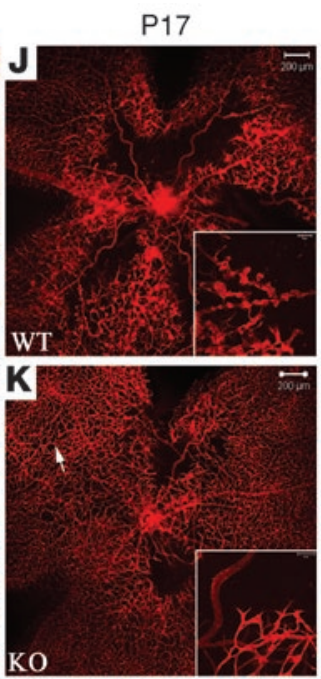

GS-lectin

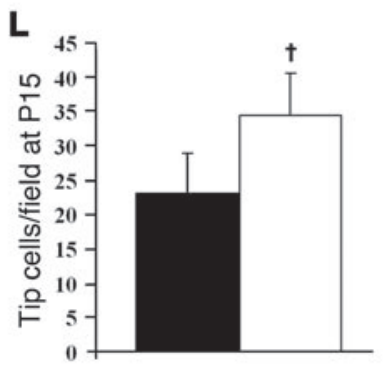

\section{Figure 4}

$\mathrm{S}_{1} \mathrm{P}_{2} \mathrm{R}$ modulates retinal vascular patterning. (A and C) At P14, S1p2+/- and S1p2-/- retinas optically sectioned at the GCL showed similar distribution of proliferative cells (BrdU staining). At P17, S1p2+/+ retinas (B) optically sectioned at the GCL showed an increased number of proliferative cells (BrdU staining) colocalizing with ECs (E, GS-lectin, white arrowhead) in the vascular tuft areas, while in S1p2 ${ }^{-/-}$retinas (D), mitogenic cells were incorporated into the central vascular bed (F, ECs-GS-lectin, white arrowhead). (G) Quantification of fluorescent pixels representing BrdU-positive cells per retina at P14: S1p2 $2^{+-}$retinas showed $0.05 \pm 0.006(n=5)$, whereas $S 1 p 2^{-/-}$retinas showed $0.05 \pm 0.011$ $\left(n=5 ;{ }^{*} P=0.47\right)$ fluorescent pixels/total retinal area. At P15, $S 1 p 2^{+/+}$retinas favored excessive growth of neovascular tufts into the vitreous (H), whereas $S 1 p 2^{-/-}$retinas favored vascular sprouts directed into the central retina (tip cells, arrows) (I). At P17, S1p2 $2^{-/-}$retinas optically sectioned at the GCL presented enhanced normal revascularization with endothelial tip cells (inset) redirected into the ischemic retina area (K), whereas $S 1 p 2^{+/+}$retinas formed abnormal vascular buds directed toward the vitreous chamber $(\mathbf{J}$, inset). (L) At the early stage of retina pathogenesis (P15), S1p2 $2^{+-}$retinas developed $23.122 \pm 5.73$ tip cells/field $(n=9)$, whereas $S 1 p 2^{-/-}$retinas developed $34.34 \pm 6.3$ tip cells/field $(n=7$; † $P<0.0025)$. Values represent mean \pm SD. Scale bars: $200 \mu \mathrm{m}(\mathbf{A}-\mathbf{D}, \mathbf{H}$, and I), $20 \mu \mathrm{m}(\mathbf{E}$ and $\mathbf{F})$, and $50 \mu \mathrm{m}(\mathbf{J}$ and $\mathbf{K})$.

architecture of the 2 additional capillary networks in IPL and OPL besides the primary vasculature of nerve fiber layer (NFL), whereas $S 1 p 2^{+/+}$retinas formed poorly organized capillary network in the OPL (Figure 3, B and A, respectively). In addition, S1p2-/mice (Supplemental Figure 3D), similar to mice maintained in normoxia, displayed normal, almost fully recovered intraretinal vasculature in close association with surrounding long astrocytic processes (Figure 3D). In $S 1 p 2^{+/+}$retinas, astrocytes (glial fibrillary acidic protein-positive [GFAP-positive] cells) covered the retinal surface, but they were not closely associated with abnormally shaped vessels in the vascular tuft areas (Figure 3C).

Furthermore, in S1p $2^{+/+}$retinas, pericyte (NG2-positive) staining was seen in all vasculature, in both normal and vascular tuft areas (Figure 3E) (24). In $S 1 p 2^{-/-}$retinas, pericyte staining was also seen in all vessels (Figure 3F and Supplemental Figure 3C), even though vascular tufts were reduced. These observations suggest that at P17 (peak of neovascularization), S1p2 $2^{-/}$retinas display normal formation of the primary as well as the deeper capillary retinal networks with proper maturation (as indicated by pericyte coverage) of the vasculature.

$S_{1} P_{2} R$ modulates vascular patterning but not proliferation in ischemic mouse retina. We next focused on cellular events regulated by the $\mathrm{S}_{1} \mathrm{P}_{2} \mathrm{R}$. To study the proliferation of retinal vessels, we performed a BrdU incorporation assay. BrdU positivity was most pronounced in ECs (GS-lectin-positive cells; Figure 4, E and F); however, a minor fraction of GFAP-positive cells (astrocytes) also incorporated BrdU (Supplemental Figure 3, A and B) (25). At P14 (very early stage of pathological neovascularization), $S 1 p 2^{+/-}$and $S 1 p 2^{-/-}$retinas exhibited similar distribution of BrdU-positive ECs in the primary vasculature (Figure 4, A and C). BrdU-positive cell numbers 

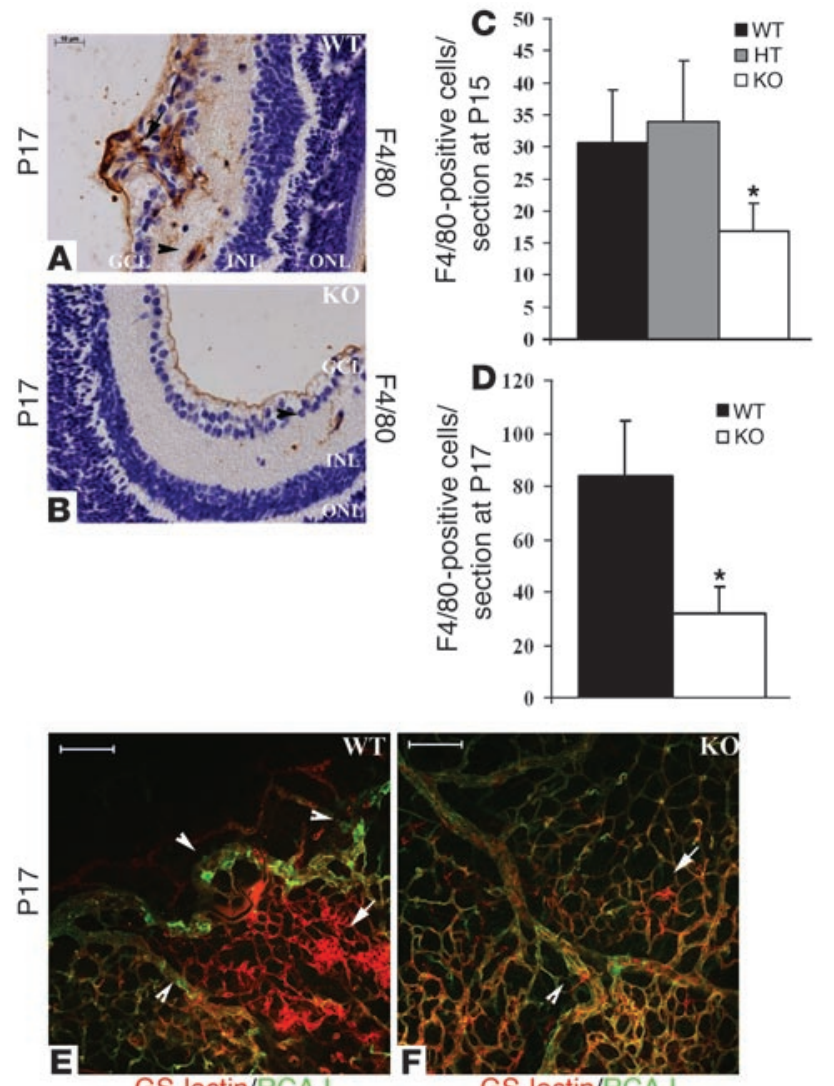

GS-lectin/RCA I were similar in $S 1 p 2^{+/-}$and $S 1 p 2^{-/-}$retinas at P14 (Figure $4 \mathrm{G}$ ). At $\mathrm{P} 17$, in $S 1 \mathrm{p}^{+/+}$retinas, proliferating cells were mostly located in the vascular tuft areas that protrude toward the vitreous (Figure $4 \mathrm{~B})$. In contrast, mitogenic ECs of $S 1 p 2^{-/-}$retinas were distributed evenly in the well-formed vascular network of the central retina (Figure 4D). These data suggest that intrinsic proliferation of ECs is not modulated by $\mathrm{S}_{1} \mathrm{P}_{2}$ signaling.

We next focused on vascular patterning as a possible mechanism

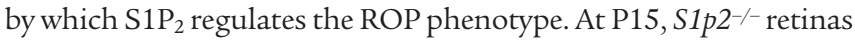
contained new vascular sprouts directed into the central avascular region of the retina, whereas $S 1 p 2^{+/+}$retinas displayed intravitreal neovascular tufts (Figure 4, I and $\mathrm{H}$, respectively). Interestingly, at $\mathrm{P} 15$ the mean number of tip cells that were directed into the avascular retina was $34.34 \pm 6.3$ in $S 1 p 2^{-/-}$retinas, whereas it was only $23.12 \pm 5.73(P<0.0025$; Figure $4 \mathrm{~L})$ for the $S 1 p 2^{+/+}$retinas. We next imaged GS-lectin-stained $S 1 p 2^{+/+}$and $S 1 p 2^{-{ }^{--}}$whole mount retinas at P17, when maximum revascularization of NFL was observed (Figure 4 , $\mathrm{J}$ and $\mathrm{K}$, respectively). Higher-magnification views in $S 1 p 2^{+/+}$ retinas revealed that growing vessels formed round, abnormal buds that were oriented toward the vitreous (Figure 4J, inset). In sharp contrast, in analogous areas of $S 1 p 2^{-/-}$retinas, long tip cells were seen at the edge of newly growing vessels that were directed toward the avascular retina (Figure $4 \mathrm{~K}$, inset). These data are consistent with the notion that $\mathrm{S}_{1} \mathrm{P}_{2} \mathrm{R}$ modulates the directionality and patterning of ECs in the context of pathologic angiogenesis.

$S 1 P_{2} R$ promotes bypoxia-driven inflammatory response in mouse retina. Pathologic angiogenesis in the mouse model of ischemiadriven retinopathy is known to be regulated by hypoxia-mediated expression of angiogenic factors such as VEGF, Ang-2, and iNOS

\section{Figure 5}

$\mathrm{S}_{1} \mathrm{P}_{2}$ regulates inflammatory response in ischemic retinas. Retinal cross sections stained with F4/80 macrophage marker show increased inflammatory response in $51 p 2^{+/+}$retinas $(\mathbf{A})$ in areas of neovascularization (arrows) and in close association with ECs between $\mathrm{GCL}$ and INL (arrowheads) compared with S1p2 $2^{-/-}$retinas (B). (C) At P15, the mean number of F4/80-positive cells was $30.57 \pm 8.23(n=2)$ for $S 1 p 2^{+/+}$retinas, $33.91 \pm 9.5(n=4)$ for $S 1 p 2^{+/-}$retinas, and $16.85 \pm 4.33$ $\left(n=4\right.$; $\left.{ }^{*} P<0.02\right)$ for $S 1 p 2^{-l-}$ retinas. (D) At P17, the mean number of F4/80-positive cells was $83.76 \pm 20.93(n=3)$ for $S 1 p 2^{+/+}$retinas and $31.81 \pm 9.88\left(n=3 ;{ }^{*} P<0.02\right)$ for $S 1 p 2^{-/-}$retinas. At P17, whole mount retinas were perfused with FITC-RCA I, which highlights endothelial gaps (arrowheads) but is excluded from nonperfused vascular tufts areas (arrows) in $S 1 p 2^{+/+}(E)$ and in $S 1 p 2^{-/-}$retinas $(F)$. Values represent mean \pm SD. Scale bars: $100 \mu \mathrm{m}(\mathbf{E}$ and $\mathbf{F})$ and $10 \mu \mathrm{m}(\mathbf{A}$ and $\mathbf{B})$.

(26-29). However, recent reports suggest that inflammation may play a crucial role during the progression of ectopic neovascularization and vascular tuft formation $(30,31)$. To test whether inflammatory response is modulated, we probed for inflammatory cells of the myeloid lineage in retinal cross sections by macrophage-specific F4/80 immunostaining (Figure 5, A and B). In P15 WT or heterozygous retinas, the number of macrophages present in the vascular tuft area was $30.57 \pm 8.23$ and $33.91 \pm 9.5$, respectively (Figure 5C). In P15 KO retinas, the number of inflammatory cells was significantly reduced to $16.85 \pm 4.33(P<0.02$; Figure $5 \mathrm{C})$. In P17 WT retinas, an increased number of macrophages was present in the vascular tuft area, in the vicinity of abnormally growing blood vessels. Moreover, macrophages with long processes were localized between the GCL and INL, representing inflammatory cells that infiltrate the tissue upon vascular damage $(83.76 \pm 20.93$ cells; Figure 5D). In sharp contrast, KO littermates displayed a markedly reduced number of macrophages between the GCL and INL in close association with vessels $(31.81 \pm 9.88$ cells; $P<0.02$; Figure $5 \mathrm{D})$. These data suggest that lack of $\mathrm{S}_{1} \mathrm{P}_{2} \mathrm{R}$ reduces inflammation in the ischemic retina.

To further investigate the involvement of inflammation, we injected FITC-conjugated Ricinus communis agglutinin I (RCA I) tracer into the left ventricle of $S 1 p 2^{+/+}$and $S 1 p 2^{-/-}$mice (P17). RCA I has been reported to label focal sites of plasma leakage and endothelial gaps of inflamed areas (32). Then retinas were dissected and stained en face with Alexa Fluor 594-conjugated GS-lectin to image the total retinal vasculature. In $S 1 p 2^{+/+}$whole mount retinas, GS-lectin staining highlighted the whole vasculature, whereas areas of vascular tufts were only partially perfused by the RCA I tracer (Figure 5E). However, in S1p2-/- mice, RCA I tracer staining pattern was very uniform and coincided with the GS-lectin staining (Figure $5 \mathrm{~F}$ ). This suggested that perfusion of retinal vasculature is efficient in the $S 1 p 2^{-/-}$retina. In addition, in $S 1 p 2^{+/+}$retinas, we observed areas with substantial RCA I extravasation into the basement membrane and abluminal space, whereas few leaky gaps were evident in $S 1 p 2^{-/-}$vessels. These data suggest that reduced vascular injury and improved blood flow of the retinal vasculature is characteristic of the S1p2 $2^{-/-}$mice at P17.

The proinflammatory enzyme COX-2 is induced by $S 1 P_{2} R$. To elucidate the molecular mechanisms involved in the regulation of retinal vascularization and intravitreal angiogenesis by $S 1 \mathrm{P}_{2} \mathrm{R}$, we measured mRNA levels of proangiogenic and proinflammatory mediators at the onset of hypoxia (P13, 24 hours hypoxia), before the initiation of pathologic neovascularization. Expres- 

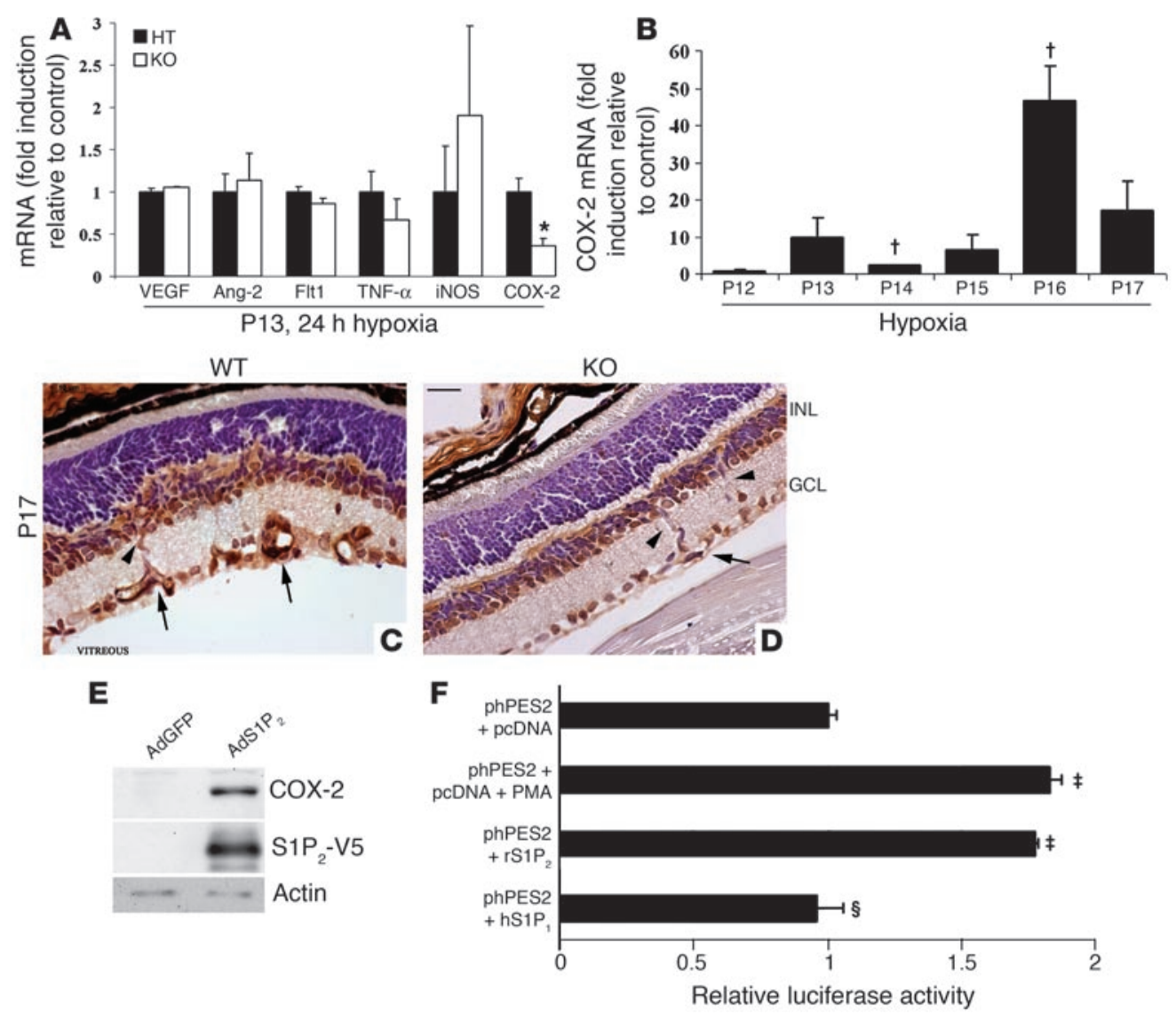

\section{Figure 6}

$\mathrm{S}_{1} \mathrm{P}_{2} \mathrm{R}$ regulates in vivo COX-2 expression during hypoxia. (A) Relative VEGF, Ang-2, Flt1, TNF- $\alpha$, iNOS, and COX-2 mRNA expression in HT and KO ischemic retinas at P13 (24 hours of hypoxia) as determined by quantitative RT-PCR $\left(n=3 ;{ }^{*} P<0.04\right)$. Gene expression was normalized to cyclophilin A expression and expressed as fold induction over the control HT animals. (B) Fold induction of relative COX-2 mRNA expression during the course of hypoxia $(n=3 ; \uparrow P<0.02)$. (C) Immunohistochemistry for COX-2 in retina cross sections of WT retinas showed strong expression in the nerve cells and vessels of the INL and GCL. (D) KO retinas displayed lower COX-2 expression in the vessels of the INL (arrowheads) and GCL (arrows). Counterstaining with hematoxylin. Scale bar: $10 \mu \mathrm{m}$. (E) Immunoblotting for COX-2, S1 $\mathrm{P}_{2}-\mathrm{V} 5$, and actin expression in HUVECs transduced with AdS1P ${ }_{2}-\mathrm{V} 5$ and AdGFP. (F) Induction of promoter activity of the human COX-2 gene. phPES2(-1432/+59) luciferase reporter $(0.3 \mu \mathrm{g})$ was cotransfected in EOMA cells with pcDNA 3.1 (control, $0.3 \mu \mathrm{g}$ ), pcDNA3.1-S1p2 receptor plasmid (0.3 $\mu \mathrm{g})$, or pcDNA3.1S1p1 receptor plasmid $(0.3 \mu \mathrm{g})$. Cells transfected with phPES2 $(-1432 /+59)$ luciferase reporter were treated with PMA (positive control, $100 \mathrm{nM}$ ). Results from 1 representative experiment are shown $\left({ }^{\ddagger} P<0.01, \S P=0.43 ; n=4\right)$.

sion of VEGF, Ang-2, and Flt1 (proangiogenic mediators) as well as TNF- $\alpha$ and iNOS (proinflammatory mediators) was similar in $S 1 p 2^{+/-}$and $S 1 p 2^{-/-}$littermates (Figure 6A). However, COX-2 expression was significantly decreased, by approximately $64 \%$, in the $S 1 p 2^{-/-}$retinas compared with $S 1 p 2^{+/-}$counterparts. In addition, in WT retinas COX-2 mRNA expression was highly induced during the course of hypoxia, peaking at P16 (4 days of hypoxia) (Figure 6B). These experiments suggest that the proinflammatory mediator COX-2 could be a target of $\mathrm{S}_{1} \mathrm{P}_{2} \mathrm{R}$ pathway, during the hypoxia-driven inflammatory response in the mouse retina (33).

To gain further insights into the cellular mechanism of COX-2 regulation by $\mathrm{S}_{1} \mathrm{P}_{2} \mathrm{R}$ in hypoxic retina, we performed immunohistochemistry in retina cross sections to localize COX-2. Interestingly, $S 1 p 2^{+/+}$retinas displayed strong COX-2 expression in the retinal nerve cells of the INL and GCL. We also observed enhanced COX-2 staining in the ECs of the INL, while COX-2 was predominantly expressed in the growing vessels of the GCL, which was similar to the tissue expression pattern of $\mathrm{S}_{\mathrm{P}} \mathrm{P}_{2} \mathrm{R}$ (Figure $6 \mathrm{C}$ and Figure 1D, respectively). In $S 1 p 2^{---}$retinas, COX-2 was still detected in nerve cells of the INL and GCL, but its expression was reduced in vessels of the INL and GCL (Figure 6D). These in vivo experiments suggest that in mouse ischemic retina, $\mathrm{S}_{1} \mathrm{P}_{2} \mathrm{R}$ function induces COX-2 expression in vascular ECs.

When $\mathrm{S}_{1} \mathrm{P}_{2} \mathrm{R}$ was expressed in HUVECs by adenoviral transduction, $\mathrm{COX}-2$ protein expression was significantly increased relatively to that of control cells transduced with adenovirus expressing GFP (AdGFP) (Figure 6E). In addition, we tested whether $\mathrm{S}_{1} \mathrm{P}_{2} \mathrm{R}$ can induce the transcription of the COX-2 gene. For this we measured human COX-2 promoter-driven (phPES2-driven) reporter activity in transfected ECs (34). As expected, the promoter activity of phPES2 that contains the 5 -flanking region $(-1432 /+59)$ of the human PTGS2 (COX-2) gene was induced 1.83-fold by PMA in mouse hemangioendothelioma (EOMA) cells. The promoter activity was induced 1.81 -fold when $S 1 p 2$ receptor was transfected, while 

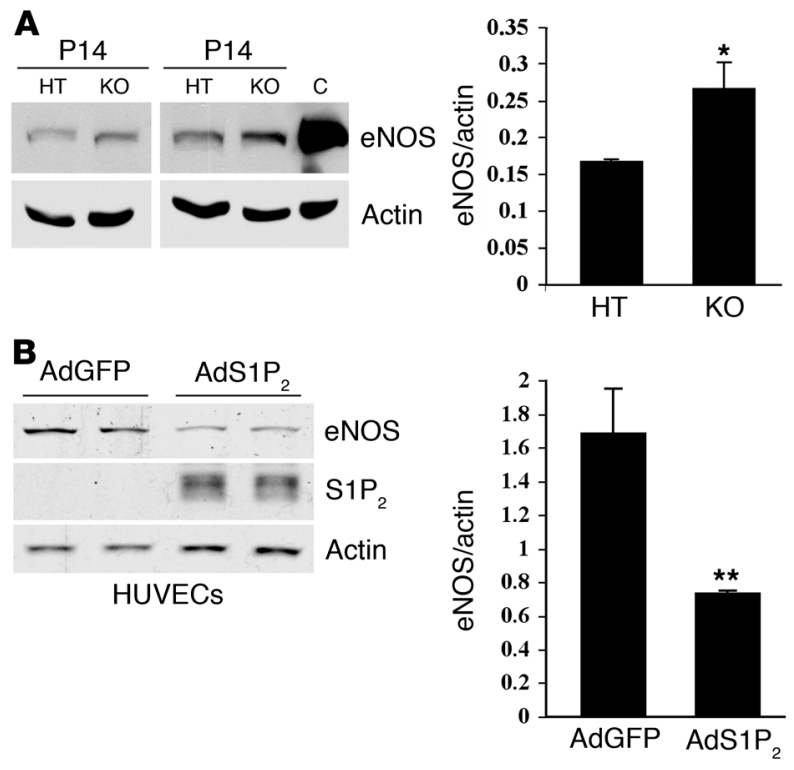

there was no induction observed in cells transfected with the S1p1 receptor (Figure $6 \mathrm{~F}$ ). These data suggest that $\mathrm{S}_{1} \mathrm{P}_{2} \mathrm{R}$ induces the proinflammatory gene COX-2 at the transcriptional level.

eNOS expression is negatively regulated by the $S 1 P_{2} R$. Ischemia-dependent angiogenesis induces eNOS activation and leads to increased NO release that consequently reduces vascular resistance, improves blood flow, and enhances vascular remodeling $(35,36)$. To explore the possibility that $\mathrm{S}_{1} \mathrm{P}_{2} \mathrm{R}$ is able to regulate eNOS function, we examined eNOS protein expression of $S 1 p 2^{+/-}$and $S 1 p 2^{-/-}$retinal extracts at the early onset of hypoxia (P14). Indeed, in S1p2 $2^{--}$retinal extracts, eNOS protein levels were significantly increased, by 1.6-fold, compared with those in S1p2+/- counterparts (Figure $7 \mathrm{~A})$. To test whether $\mathrm{S}_{1} \mathrm{P}_{2} \mathrm{R}$ directly regulates eNOS expression, we quantified eNOS levels when the $\mathrm{S}_{1} \mathrm{P}_{2} \mathrm{R}$ was expressed in vitro. When $S 1 p 2$ receptor-containing adenovirus was transduced into HUVECs, eNOS protein expression was significantly reduced, by approximately 2.3-fold, relative to that in control cells (Figure 7B). The effect was partially blocked by inhibition of the Rho-associated protein kinase (ROCK), a key mediator of $\mathrm{S}_{1} \mathrm{P}_{2}$ signaling (37) (Supplemental Figure 4). These results suggest that $\mathrm{S}_{1} \mathrm{P}_{2} \mathrm{R}$ negatively regulates eNOS expression.

\section{Discussion}

The present study investigates the role of S1P signaling in retinal vascular development and abnormal angiogenesis in the ROP model. Although ceramide metabolism has been implicated in retinal photoreceptor function and endocytosis, as well as in diabetic retinopathy, the functional role of S1P in retinal development and pathology has not been addressed $(38,39)$. This is particularly important as $\mathrm{S} 1 \mathrm{P}$ is now accepted as an angiogenic factor and an inducer of vascular maturation (6). A recent report suggests that inhibitors of sphingosine kinase, an enzyme that generates S1P ligand, reduced retinal vascular leakage in the rat diabetic retinopathy model (40). The role of S1P receptors in retinal vasculature has not to our knowledge been addressed previously. We report here that $\mathrm{S}_{1} \mathrm{P}_{2} \mathrm{R}$ is induced during ischemia-driven retinopathy, peaking at the growth phase of pathologic neovascularization. Immunohistochemistry experiments demonstrated that it is

\section{Figure 7}

$\mathrm{S}_{1} \mathrm{P}_{2} \mathrm{R}$ negatively regulates eNOS expression during hypoxia. (A) eNOS and actin protein expression in HT and KO retinas at P14 (2 days of hypoxia); HUVEC extract was used as positive control. eNOS expression was increased by 1.6 -fold in $\mathrm{KO}$ retinas $\left({ }^{*} P \leq 0.05\right)(\mathrm{B})$ Western blot analysis of extracts from HUVECs transduced with AdGFP or AdS1P $\mathrm{P}_{2}-\mathrm{V} 5$ (20 MOI). Immunoblotting for eNOS, S1 $\mathrm{P}_{2}-\mathrm{V} 5$, and actin expression. Levels of eNOS in HUVECs transduced with AdS $1 \mathrm{P}_{2}-\mathrm{V} 5$ were decreased by 2.3 -fold ( ${ }^{* *} P<0.02$; results from 1 representative experiment, $n=5$ ).

expressed in the growing vessels of the INL and GCL, highlighting structures of vascular tufts. It is likely that either hypoxia per se or hypoxia-responsive regulators such as VEGF and Ang-2 could modulate $\mathrm{S} 1 \mathrm{P}_{2} \mathrm{R}$ expression.

We quantified S1P levels in retina tissue with a highly specific HPLC method (41) and found only low levels (5-30 pmol/mg of protein) (data not shown). This contrasts with the high S1P levels found in plasma $(\sim 0.4-1 \mu \mathrm{M})(42)$. Therefore, during retinal hypoxia, concomitant vascular permeability would likely result in $\mathrm{S} 1 \mathrm{P}$ release in the interstitial milieu of the retina, which may activate the $\mathrm{S}_{1} \mathrm{P}_{2} \mathrm{R}$ on the vascular ECs.

A major finding of this work is that the $\mathrm{S}_{1} \mathrm{P}_{2} \mathrm{R}$ is essential for the pathologic angiogenesis of the retina. At P15 and P17, pathological intravitreal neovascularization was decreased by approximately $50 \%$ in $S 1 p 2^{-/-}$retinas. Importantly, $S 1 p 2^{-/-}$retinas display enhanced intraretinal revascularization. Enhanced physiological revascularization in the $S 1 p 2^{-/-}$retina was further confirmed by staining whole mount retinas for astrocytes (astroglia) and pericytes (mural cells), which were associated closely with ECs. Thus, lack of $\mathrm{S}_{1} \mathrm{P}_{2}$ shifted the phenotype of the ischemic retinal vasculature from pathologic to normal.

To further probe cellular mechanisms, we quantified EC proliferation; however, the same number of BrdU-positive ECs was observed in both WT and KO retinas at the beginning of pathogenesis (P14), suggesting that regulation of cell proliferation by $\mathrm{S}_{1} \mathrm{P}_{2}$ is unlikely to be the primary mechanism involved. Interestingly, detailed examination of the growing vessels at the beginning of neovascularization suggested that $S 1 \mathrm{p}^{-{ }^{-/}}$mice display an increased number of ECs with elongated processes (tip cells) that are oriented toward the avascular regions compared with $S 1 \mathrm{p}^{+/+}$ mice. This alteration in normal vascular patterning may be disrupted by increased expression and signaling of $\mathrm{S}_{1} \mathrm{P}_{2}$ in the ECs, thus allowing misdirected angiogenesis in the vitreous chamber and concomitant reduced normal retina revascularization. It is possible that exaggerated $\mathrm{S}_{1} \mathrm{P}_{2}$ signaling in ECs could contribute to patterning defects. We speculate that retinal endothelial tip cell directionality, which is regulated by signaling pathways such as $\operatorname{VEGF}(23)$ and Notch $(37,43)$, may be disrupted by aberrant $\mathrm{S}_{1} \mathrm{P}_{2}$ signaling in the context of ROP. As discussed below, such processes may also be influenced by inflammation.

Another key finding of this study is that $\mathrm{S}_{1} \mathrm{P}_{2} \mathrm{R}$ regulates inflammatory events in ROP. WT retinas appear to be poorly perfused in areas of vascular tufts, whereas there are evident endothelial gaps and extravasation of the tracer into the abluminal space. In sharp contrast, at P17 S1p2-null retinas have improved blood flow and reduced leaky inflamed focal sites. This is consistent with our recent study, wherein we showed that $\mathrm{S}_{1} \mathrm{P}_{2} \mathrm{R}$ induced Rho- and PTEN-dependent paracellular permeability in ECs and oxidantinduced lung vascular permeability (44). This increase in vascular 
permeability in the ischemic retinal vasculature is likely the key initiator of the inflammatory events. Indeed, F4/80-positive myeloid cells was observed in the vascular tufts in WT animals, whereas fewer inflammatory cells were associated with the retinal tissue of $\mathrm{KO}$ animals even at the very beginning of the pathogenesis.

Inflammatory mechanisms are thought to contribute to pathologic intravitreal angiogenesis $(45,46)$. iNOS inhibits angiogenesis in the avascular retina through the VEGF/VEGR2 axis, thus leading to increased intravitreal angiogenesis (29). Ritter et al. showed that activated microglia contributes to enhanced revascularization by restoring appropriate gradient of angiogenic factors (31). Our data suggest that $\mathrm{S}_{1} \mathrm{P}_{2} \mathrm{R}$-dependent inflammatory response may be important in the initiation and progression of abnormal ocular angiogenesis. Furthermore, abnormal intravitreal angiogenesis and normal retinal vascularization vessel may be interdependent. Our data suggest that S1P signaling via $\mathrm{S}_{1} \mathrm{P}_{2} \mathrm{R}$ may alter the balance between these processes.

In order to gain insight into the molecular mechanisms by which $\mathrm{S}_{1} \mathrm{P}_{2} \mathrm{Rs}$ facilitate intravitreal neovascularization, we profiled the expression of proangiogenic and proinflammatory molecules. We found that expression of the proinflammatory molecule COX-2 is significantly reduced in $\mathrm{KO}$ retinas. This observation is in agreement with previous reports that identify COX-2 as a promoter of retinal and corneal neovascularization, as well as tumor angiogenesis $(33,47,48)$. Indeed, COX-2-specific inhibitors significantly reduced vascular tufts in the $\operatorname{ROP}$ model $(33,49)$. We propose that in the ischemic retina, $\mathrm{S}_{1} \mathrm{P}_{2} \mathrm{R}$ induces $\mathrm{COX}-2$, leading to increased inflammatory response and enhanced intravitreal neovascularization most likely through proangiogenic $\mathrm{PGE}_{2}(30,50-53)$.

However, COX-2 inhibitor treatment did not stimulate normal retinal vascularization, suggesting that additional targets regulated by $\mathrm{S}_{1} \mathrm{P}_{2}$ are involved. We propose that eNOS may be one such molecule. We observed that at the early stage of pathologi-

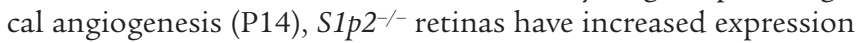
of eNOS protein in comparison with $S 1 p 2^{+/+}$retinas. By performing in vitro experiments in ECs, we show that $S 1 P_{2} R$ can directly downregulate eNOS protein expression. eNOS is a major source of NO, a potent vasodilator that facilitates proper blood flow and inhibits microvascular congestion $(54,55)$. Interestingly, our observations are somewhat discordant with a previous study in which eNOS-deficient mice developed reduced intravitreal neovascularization in oxygen-induced retinopathy (56). This may be due to the fact that eNOS-deficient mice are less susceptible to hyperoxia-induced pruning of the vessels from P7 to P12, whereas we observed increased eNOS expression in S1p2-/- hypoxic retinas at P14. In addition, the pharmacologic NOS inhibitor (L-NNA) that was used for these studies appears to be a competitive nonselective inhibitor of all 3 NOS isoforms (eNOS, neuronal NOS [nNOS], and iNOS). It has been reported that eNOS mRNA stability is reduced under hypoxic conditions or upon thrombin stimulation and inflammation (57-59). Interestingly, Rho/ROCK-associated kinase activation that is downstream of the $\mathrm{S}_{1} \mathrm{P}_{2} / \mathrm{G}_{12 / 13}$ receptor pathway is known to mediate hypoxia-dependent inhibition of eNOS expression in ECs $(60,61)$. Thus, we speculate that in ischemic retinas, $\mathrm{S}_{1} \mathrm{P}_{2} \mathrm{R}$ negatively regulates eNOS expression, possibly through the Rho/Rho kinase pathway, which may contribute to retinal vascular congestion and pathological angiogenesis.

In conclusion, we show for the first time to our knowledge that the $\mathrm{S}_{1} \mathrm{P}_{2} \mathrm{R}$ pathway is an essential inducer of pathological neovascularization and inhibits hypoxia-triggered revascularization in the retina. In this regard we suggest that therapeutic compounds that specifically inhibit $S 1 P_{2} G$ protein-coupled receptor would inhibit pathologic angiogenesis while promoting physiological revascularization of the ischemic retina. Regulation of the plasticity of vascular phenotype by $\mathrm{S}_{1} \mathrm{P}_{2}$ may also be useful in other ischemia-driven vascular diseases.

\section{Methods}

Animals. C57BL/ $6 \times 129$ Sv mice with targeted disruption of the S1p2 gene were generated as previously reported (13). Mice were maintained on a mixed C57BL/6 $\times 129 \mathrm{~Sv}$ genetic background, and experiments on KO mice were performed with appropriate littermate controls. All procedures involving mice were approved by the University of Connecticut Health Center Animal Care Committee. ROP was induced according to a protocol established by Smith et al. (20). Briefly, pups (P7) with nursing mother were transferred into an air-tight incubator and were exposed to an atmosphere of $74 \% \pm 1 \%$ oxygen for 5 days. At P12, pups were returned to room air.

RNA isolation and RT-PCR analysis. RNA was extracted (RNeasy kit; QIAGEN) from mouse retinas. First-strand cDNA was synthesized using random hexamers, murine leukemia virus reverse transcriptase, and accompanying reagents (Invitrogen) for 1 hour at $37^{\circ} \mathrm{C}$. Mouse RT-PCR primers shown in Supplemental Table 1 were designed with Primer Express software (version 2.0; Applied Biosystems). Amplification and data analysis were performed with an ABI Prism 7900HT Sequence Detection System (Applied Biosystems). mRNA levels were quantified and corrected for cyclophilin A and expressed as fold induction over the corresponding control.

Histology and immunohistochemistry. For intravitreal neovascularization, 12 sections ( $6 \mu \mathrm{m}$ thick, $30 \mu \mathrm{m}$ apart) from each eyeball were PAS and hematoxylin stained (PAS kit; Sigma-Aldrich). Vascular cell nuclei growing beyond the INL were counted. For $\mathrm{S}_{1} \mathrm{P}_{2}$ staining, heat epitope retrieval of tissue sections was performed in $10 \mathrm{mM}$ citrate buffer ( $\mathrm{pH}$ 6.0). For F4/80 and COX-2 staining, tissue sections were pretreated with Pronase E (SigmaAldrich) for 5 minutes. Sections were stained with primary antibody overnight at $4{ }^{\circ} \mathrm{C}$ : rabbit polyclonal anti-S1 $\mathrm{P}_{2} \mathrm{R}(62,63)(1: 200)$, mouse antiF4/80 (1:100; BD Biosciences - Pharmingen), rabbit anti-COX-2 (1:800; Cayman Chemical). Primary antibody detection was performed with VECTASTAIN ABC kit (Vector Laboratories). Counterstaining was performed with methyl green or Mayer hematoxylin.

Retina whole mount preparation, quantification of avascular area, and immunofluorescence. Eyes were enucleated and fixed in 4\% PFA for 15 minutes. Retinas were dissected out and postfixed for 15 minutes. To visualize endothelium, retinas were stained with Alexa Fluor 594-conjugated GS-lectin (20 $\mu \mathrm{g} / \mathrm{ml}$; Molecular Probes; Invitrogen). Primary antibodies were: FITC-conjugated mouse anti- $\alpha$-SMA (1:100; Sigma-Aldrich), rabbit anti-GFAP (1:200; Dako), rabbit anti-NG2 (1:200; Chemicon), mouse anti-BrdU (1:200; Chemicon). Secondary antibodies were: Alexa Fluor 488-conjugated goat antirabbit antibody (1:200; Molecular Probes; Invitrogen). Retinas were visualized using a Zeiss LSM 510 confocal microscope. Avascular and total retina areas were quantified with ImageJ software (http://rsb.info.nih.gov/ij/). For FITC-RCA I ( $50 \mu \mathrm{l}, 2 \mathrm{mg} / \mathrm{ml}$; Vector Laboratories) perfusion, mice were anesthetized with Avertin (Sigma-Aldrich), injected in the left ventricle with RCA I, which was allowed to circulate for 2 minutes. Unbound lectin was removed with $1 \%$ BSA-PBS perfusion for 1 minute followed by $4 \%$ PFAPBS fixation for 5 minutes. Eyes were enucleated, postfixed, and stained as described above. For tip cell quantification, sprouts were counted in 4 different fields of the retinal mid-periphery, and the mean number of tip cells per retina was calculated. For BrdU-positive cell quantification, Image-Pro Plus image analysis software (version 5.1.1.38; MediaCybernetics) was used to count fluorescent pixels per total retinal area.

Luciferase activity experiments. EOMA cultures $\left(3 \times 10^{5}\right.$ cells/well $)$ on a 6 -well plate were grown 1 day before the transfection. To measure transfec- 
tion efficiency, cells were cotransfected with pCMV- $\beta$-gal. For each well, $0.3 \mu \mathrm{g}$ of the luciferase reporter vector phPES2 $(-1432 /+59), 0.3 \mu \mathrm{g}$ of the gene of interest (pcDNA3.1-S1p2 or pcDNA3.1-S1p1), and $25 \mathrm{ng}$ of pCMV- $\beta$-gal mixed with Lipofectamine 2000 (Invitrogen) were introduced into the cells as described by the manufacturer. Twenty-four hours after transfection, cells were treated with PMA $(100 \mathrm{nM})$ for 5 hours, if necessary. Cells were harvested, and luciferase and $\beta$-gal activity were determined with a Luciferase Assay System (Promega) and Western-Light and Western-Star system (Applied Biosystems), respectively. The amount of plasmid DNA was made constant by adding pcDNA 3.1, and luciferase activity was normalized to micrograms of protein content.

Western blot analysis. Retinas or cells were solubilized in $2 \times$ SDS sample buffer (20 mM DTT, 6\% SDS, 0.25 M Tris pH 6.8, 10\% glycerol, bromophenyl blue, protease inhibitors, $1 \mathrm{mM}$ sodium orthovanadate, and $1 \mathrm{mM}$ $\mathrm{NaF}$ ), sonicated, boiled and separated by SDS-PAGE gel electrophoresis. Membranes were incubated with the following antibodies: anti-actin (Sigma-Aldrich), anti-eNOS (BD Biosciences - Pharmingen), anti-COX-2 (Cayman), and anti-V5 (Invitrogen). Cells were treated overnight with 10 $\mu \mathrm{m}$ Y-27632 (Calbiochem). Immunoreactive band density was quantified with IQMac version 1.2 software (Molecular Dynamics).

Adenoviral vector construction and production. $\mathrm{cDNA}$ encoding $\mathrm{S}_{\mathrm{P}}$-V5 tag was subcloned into the pShuttle-CMV vector that was used to produce recombinant adenovirus using bacteria-AdEasy vector system (AdEasy kit; Quantum Biotechnologies) as described by the manufacturer.

Statistics. Statistical differences were assessed using the 2-tailed Student's $t$ test. $P$ values less than 0.05 were considered significant.

\section{Acknowledgments}

We would like to acknowledge $\mathrm{H}$. Inoue for the kind gift of human COX-2 luciferase reporter vector phPES2 $(-1432 /+59)$ and Mingtao Wu for his essential technical assistance with adenovirus construction. This work is supported by NIH grants R37HL67330, PO1-HL70694, and PO1-CA77839 to T. Hla and intramural program funds of the NIDDK, NIH, to R.L. Proia. T. Sanchez is supported in part by a Scientist Development Grant from the American Heart Association.

Received for publication December 4, 2006, and accepted in revised form May 29, 2007.

Address correspondence to: Timothy Hla, Center for Vascular Biology, University of Connecticut School of Medicine, 263 Farmington Avenue, Farmington, Connecticut 06030-3501, USA. Phone: (860) 679-4128; Fax: (860) 679-1201; E-mail: hla@nso2.uchc.edu.
1. Spiegel, S., and Milstien, S. 2003. Sphingosine-1phosphate: an enigmatic signalling lipid. Nat. Rev. Mol. Cell Biol. 4:397-407.

2. Saba, J.D., and Hla, T. 2004. Point-counterpoint of sphingosine 1-phosphate metabolism. Circ. Res. 94:724-734

3. Lee, M.J., et al. 1998. Sphingosine-1-phosphate as a ligand for the $\mathrm{G}$ protein-coupled receptor EDG-1. Science. 279:1552-1555.

4. Windh, R.T., et al. 1999. Differential coupling of the sphingosine 1-phosphate receptors Edg-1, Edg-3, and H218/Edg-5 to the G(i), G(q), and G(12) families of heterotrimeric $\mathrm{G}$ proteins. J. Biol. Chem. 274:27351-27358.

5. Sanchez, T., and Hla, T. 2004. Structural and functional characteristics of S1P receptors. J. Cell. Biochem. 92:913-922.

6. Hla, T. 2004. Physiological and pathological actions of sphingosine 1-phosphate. Semin. Cell Dev. Biol. 15:513-520.

7. Chae, S.S., Paik, J.H., Furneaux, H., and Hla, T. 2004. Requirement for sphingosine 1-phosphate receptor- 1 in tumor angiogenesis demonstrated by in vivo RNA interference. J. Clin. Invest. 114:1082-1089. doi:10.1172/JCI200422716.

8. LaMontagne, K., et al. 2006. Antagonism of sphingosine-1-phosphate receptors by FTY720 inhibits angiogenesis and tumor vascularization. Cancer Res. 66:221-231.

9. Sanchez, T., et al. 2003. Phosphorylation and action of the immunomodulator FTY720 inhibits vascular endothelial cell growth factor-induced vascular permeability. J. Biol. Chem. 278:47281-47290.

10. Sanna, M.G., et al. 2006. Enhancement of capillary leakage and restoration of lymphocyte egress by a chiral S1P1 antagonist in vivo. Nat. Chem. Biol. 2:434-441.

11. Liu, Y., et al. 2000. Edg-1, the G protein-coupled receptor for sphingosine-1-phosphate, is essential for vascular maturation. J. Clin. Invest. 106:951-961.

12. Paik, J.H., et al. 2004. Sphingosine 1-phosphate receptor regulation of $\mathrm{N}$-cadherin mediates vascular stabilization. Genes Dev. 18:2392-2403.

13. Kono, M., et al. 2004. The sphingosine-1-phosphate receptors S1P1, S1P2, and S1P3 function coordinately during embryonic angiogenesis. J. Biol. Chem. 279:29367-29373.

14. Kono, M., et al. 2007. Deafness and stria vascularis defects in S1P2 receptor null mice. J. Biol. Chem. 282:10690-10696.

15. Herr, D.R., et al. 2007. Sphingosine 1-phosphate (S1P) signaling is required for maintenance of hair cells mainly via activation of S1P2. J. Neurosci. 27:1474-1478.

16. Kupperman, E., An, S., Osborne, N., Waldron, S., and Stainier, D.Y. 2000. A sphingosine-1-phosphate receptor regulates cell migration during vertebrate heart development. Nature. 406:192-195.

17. Connolly, S.E., Hores, T.A., Smith, L.E., and D'Amore, P.A. 1988. Characterization of vascular development in the mouse retina. Microvasc. Res. 36:275-290.

18. Gariano, R.F., and Gardner, T.W. 2005. Retinal angiogenesis in development and disease. Nature. 438:960-966.

19. Saint-Geniez, M., and D’Amore, P.A. 2004. Development and pathology of the hyaloid, choroidal and retinal vasculature. Int. J. Dev. Biol. 48:1045-1058.

20. Smith, L.E., et al. 1994. Oxygen-induced retinopathy in the mouse. Invest. Ophthalmol. Vis. Sci. 35:101-111.

21. Pierce, E.A., Avery, R.L., Foley, E.D., Aiello, L.P., and Smith, L.E. 1995. Vascular endothelial growth factor/vascular permeability factor expression in a mouse model of retinal neovascularization. Proc. Natl. Acad. Sci. U. S. A. 92:905-909.

22. Hackett, S.F., et al. 2000. Angiopoietin 2 expression in the retina: upregulation during physiologic and pathologic neovascularization. J. Cell. Physiol. 184:275-284

23. Gerhardt, H., et al. 2003. VEGF guides angiogenic sprouting utilizing endothelial tip cell filopodia. J. Cell Biol. 161:1163-1177.

24. Chan-Ling, T., et al. 2004. Desmin ensheathment ratio as an indicator of vessel stability: evidence in normal development and in retinopathy of prematurity. Am. J. Pathol. 165:1301-1313.

25. Uemura, A., Kusuhara, S., Wiegand, S.J., Yu, R.T., and Nishikawa, S. 2006. Tlx acts as a proangiogenic switch by regulating extracellular assembly of fibronectin matrices in retinal astrocytes. J. Clin. Invest. 116:369-377. doi:10.1172/JCI25964.

26. Shih, S.C., Ju, M., Liu, N., and Smith, L.E. 2003. Selective stimulation of VEGFR-1 prevents oxygen-induced retinal vascular degeneration in retinopathy of prematurity. J. Clin. Invest. 112:50-57. doi:10.1172/JCI200317808.
27. Aiello, L.P., et al. 1995. Suppression of retinal neovascularization in vivo by inhibition of vascular endothelial growth factor (VEGF) using soluble VEGF-receptor chimeric proteins. Proc. Natl. Acad. Sci. U. S. A. 92:10457-10461.

28. Hackett, S.F., Wiegand, S., Yancopoulos, G., and Campochiaro, P.A. 2002. Angiopoietin-2 plays an important role in retinal angiogenesis. J. Cell. Physiol. 192:182-187.

29. Sennlaub, F., Courtois, Y., and Goureau, O. 2001. Inducible nitric oxide synthase mediates the change from retinal to vitreal neovascularization in ischemic retinopathy. J. Clin. Invest. 107:717-725.

30. Ishida, S., et al. 2003. VEGF164-mediated inflammation is required for pathological, but not physiological, ischemia-induced retinal neovascularization. J. Exp. Med. 198:483-489.

31. Ritter, M.R., et al. 2006. Myeloid progenitors differentiate into microglia and promote vascular repair in a model of ischemic retinopathy. J. Clin. Invest. 116:3266-3276. doi:10.1172/JCI29683.

32. Thurston, G., Baluk, P., Hirata, A., and McDonald, D.M. 1996. Permeability-related changes revealed at endothelial cell borders in inflamed venules by lectin binding. Am. J. Physiol. 271:H2547-H2562.

33. Sennlaub, F., et al. 2003. Cyclooxygenase-2 in human and experimental ischemic proliferative retinopathy. Circulation. 108:198-204.

34. Inoue, H., Umesono, K., Nishimori, T., Hirata, Y., and Tanabe, T. 1999. Glucocorticoid-mediated suppression of the promoter activity of the cyclooxygenase- 2 gene is modulated by expression of its receptor in vascular endothelial cells. Biochem. Biophys. Res. Commun. 254:292-298.

35. Yu, J., et al. 2005. Endothelial nitric oxide synthase is critical for ischemic remodeling, mural cell recruitment, and blood flow reserve. Proc. Natl. Acad. Sci. U. S. A. 102:10999-11004.

36. Dudzinski, D.M., Igarashi, J., Greif, D., and Michel, T. 2006. The regulation and pharmacology of endothelial nitric oxide synthase. Annu. Rev. Pharmacol. Toxicol. 46:235-276.

37. Hofmann, J.J., and Luisa Iruela-Arispe, M. 2007. Notch expression patterns in the retina: an eye on receptor-ligand distribution during angiogenesis. Gene Expr. Patterns. 7:461-470.

38. Fox, T.E., et al. 2006. Diabetes alters sphingolipid metabolism in the retina: a potential mechanism 
of cell death in diabetic retinopathy. Diabetes. 55:3573-3580.

39. Acharya, U., et al. 2003. Modulating sphingolipid biosynthetic pathway rescues photoreceptor degeneration. Science. 299:1740-1743.

40. Maines, L.W., French, K.J., Wolpert, E.B., Antonetti, D.A., and Smith, C.D. 2006. Pharmacologic manipulation of sphingosine kinase in retinal endothelial cells: implications for angiogenic ocular diseases. Invest. Ophthalmol. Vis. Sci. 47:5022-5031.

41. Min, J.K., Yoo, H.S., Lee, E.Y., Lee, W.J., and Lee, Y.M. 2002. Simultaneous quantitative analysis of sphingoid base 1-phosphates in biological samples by o-phthalaldehyde precolumn derivatization after dephosphorylation with alkaline phosphatase. Anal. Biochem. 303:167-175.

42. Venkataraman, K., et al. 2006. Extracellular export of sphingosine kinase-1a contributes to the vascular S1P gradient. Biochem. J. 397:461-471.

43. Hellstrom, M., et al. 2007. Dll4 signalling through Notch1 regulates formation of tip cells during angiogenesis. Nature. 445:776-780.

44. Sanchez, T., et al. 2007. Induction of vascular permeability by the sphingosine-1-phosphate receptor2 (S1P2R) and its downstream effectors ROCK and PTEN. Arterioscler. Thromb. Vasc. Biol. 27:1312-1318.

45. Otani, A., et al. 2002. Bone marrow-derived stem cells target retinal astrocytes and can promote or inhibit retinal angiogenesis. Nat. Med. 8:1004-1010.

46. Kaur, C., Sivakumar, V., and Foulds, W.S. 2006. Early response of neurons and glial cells to hypoxia in the retina. Invest. Ophthalmol. Vis. Sci. 47:1126-1141.

47. Hernandez, G.L., et al. 2001. Selective inhibition of vascular endothelial growth factor-mediated angiogenesis by cyclosporin $\mathrm{A}$ : roles of the nuclear factor of activated $\mathrm{T}$ cells and cyclooxygenase 2 . J. Exp. Med. 193:607-620.

48. Tsujii, M., et al. 1998. Cyclooxygenase regulates angiogenesis induced by colon cancer cells [erratum, 1998, 94:following 271]. Cell. 93:705-716.

49. Wilkinson-Berka, J.L., Alousis, N.S., Kelly, D.J., and Gilbert, R.E. 2003. COX-2 inhibition and retinal angiogenesis in a mouse model of retinopathy of prematurity. Invest. Ophthalmol. Vis. Sci. 44:974-979.

50. Leahy, K.M., et al. 2002. Cyclooxygenase-2 inhibition by celecoxib reduces proliferation and induces apoptosis in angiogenic endothelial cells in vivo. Cancer Res. 62:625-631.

51. Liu, X.H., et al. 2002. Prostaglandin E2 induces hypoxia-inducible factor-1alpha stabilization and nuclear localization in a human prostate cancer cell line. J. Biol. Chem. 277:50081-50086.

52. Jones, M.K., et al. 1999. Inhibition of angiogenesis by nonsteroidal anti-inflammatory drugs: insight into mechanisms and implications for cancer growth and ulcer healing. Nat. Med. 5:1418-1423.

53. Chang, S.H., et al. 2004. Role of prostaglandin E2dependent angiogenic switch in cyclooxygenase 2induced breast cancer progression. Proc. Natl. Acad. Sci.U. S. A. 101:591-596.

54. Sasaki, K., et al. 2006. Ex vivo pretreatment of bone marrow mononuclear cells with endothelial NO synthase enhancer AVE9488 enhances their functional activity for cell therapy. Proc. Natl. Acad. Sci. U. S. A. 103:14537-14541.

55. Limbourg, F.P., et al. 2002. Rapid nontranscriptional activation of endothelial nitric oxide synthase mediates increased cerebral blood flow and stroke protection by corticosteroids [erratum 2003, 111:759]. J. Clin. Invest. 110:1729-1738.
doi:10.1172/JCI200215481.

56. Brooks, S.E., et al. 2001. Reduced severity of oxygen-induced retinopathy in eNOS-deficient mice. Invest. Ophthalmol. Vis. Sci. 42:222-228.

57. Eto, M., et al. 2001. Thrombin suppresses endothelial nitric oxide synthase and upregulates endothelin-converting enzyme- 1 expression by distinct pathways: role of Rho/ROCK and mitogenactivated protein kinase. Circ. Res. 89:583-590.

58. Hernandez-Perera, O., et al. 1998. Effects of the 3-hydroxy-3-methylglutaryl-CoA reductase inhibitors, atorvastatin and simvastatin, on the expression of endothelin-1 and endothelial nitric oxide synthase in vascular endothelial cells. J. Clin. Invest. 101:2711-2719.

59. Liao, J.K., et al. 1995. Regulation of bovine endothelial constitutive nitric oxide synthase by oxygen. J. Clin. Invest. 96:2661-2666.

60. Sanchez, T., et al. 2005. PTEN as an effector in the signaling of antimigratory $\mathrm{G}$ protein-coupled receptor. Proc. Natl. Acad. Sci. U. S. A. 102:4312-4317.

61. Takemoto, M., Sun, J., Hiroki, J., Shimokawa, H., and Liao, J.K. 2002. Rho-kinase mediates hypoxiainduced downregulation of endothelial nitric oxide synthase. Circulation. 106:57-62.

62. Singer, I.I., et al. 2005. Sphingosine-1-phosphate agonists increase macrophage homing, lymphocyte contacts, and endothelial junctional complex formation in murine lymph nodes. J. Immunol. 175:7151-7161

63. Forrest, M., et al. 2004. Immune cell regulation and cardiovascular effects of sphingosine 1-phosphate receptor agonists in rodents are mediated via distinct receptor subtypes. J. Pharmacol. Exp. Ther. 309:758-768. 